\title{
BMJ Open Disease burden and cost of hidradenitis suppurativa: a retrospective examination of US administrative claims data
}

\author{
Jessica Marvel (D) , ${ }^{1}$ Anna Vlahiotis, ${ }^{2}$ Amy Sainski-Nguyen, ${ }^{2}$ Tina Willson, ${ }^{2}$ \\ Alexandra Kimball ${ }^{3,4}$
}

To cite: Marvel J, Vlahiotis A, Sainski-Nguyen A, et al. Disease burden and cost of hidradenitis suppurativa: a retrospective examination of US administrative claims data. BMJ Open 2019;9:e030579. doi:10.1136/ bmjopen-2019-030579

- Prepublication history and additional material for this pape are available online. To view please visit the journal (http:// dx.doi.org/10.1136/bmjopen2019-030579).

Received 20 March 2019 Revised 16 August 2019 Accepted 02 September 2019

Check for updates

(c) Author(s) (or their employer(s)) 2019. Re-use permitted under CC BY-NC. No commercial re-use. See rights and permissions. Published by BMJ.

${ }^{1}$ Department of Health Economics and Outcomes Research, Novartis Pharmaceuticals Corp, East Hanover, New Jersey, USA ${ }^{2}$ Department of Life Sciences, IBM Watson Health, Bethesda, Maryland, USA

${ }^{3}$ Department of Dermatology, Harvard Medical School, Boston, Massachusetts, USA

${ }^{4}$ Department of Dermatology, Beth Israel Deaconess Medical Center, Boston, Massachusetts, USA

Correspondence to

Jessica Marvel;

jessica.marvel@novartis.com

\section{ABSTRACT}

Objectives Hidradenitis suppurativa (HS) causes substantial morbidity and quality-of-life impairment. We examined demographic/clinical characteristics of patients with HS and treatment patterns, prevalence and healthcare resource utilisation/expenditures related to HS in the realworld.

Design Retrospective claims data of MarketScan Commercial, Medicare Supplemental and Medicaid databases (2009-2014).

\section{Setting USA.}

Participants Patients aged $\geq 12$ years with $\geq 3$ nondiagnostic outpatient or inpatient claims with an HS diagnosis code and $\geq 12$ months continuous enrolment with medical and pharmacy benefits before (preindex) and after (postindex) the earliest diagnosis of HS (index) were included.

Results There were 11325 Commercial/Medicare patients (mean age 37.4 years) and 5164 Medicaid patients (mean age 28.3 years). HS was more common in Medicaid than Commercial/Medicare patients $(0.301 \%$ and $0.098 \%$, respectively, in 2014). Cellulitis and psychiatric disorders were the most common comorbidities and oral antibiotics and narcotics were the most frequently prescribed drugs preindex, with $\geq 10 \%$ increase postindex in both populations. HS-related inpatient costs decreased while outpatient costs increased from preindex to postindex. Medicaid patients had several risk factors that may be associated with poor outcomes (eg, high rates of prescription pain medication use, comorbidities, drug discontinuation/interruption/holiday, emergency department (ED) visits and hospitalisation).

Conclusions Commercial/Medicare and Medicaid HS beneficiaries experience high comorbidity burden but use different treatment modalities to manage HS. Results suggest a substantial unmet need exists among this patient population, with Medicaid patients experiencing a particularly high burden of disease and expensive healthcare resource utilisation.

\section{INTRODUCTION}

Hidradenitis suppurativa (HS) is a chronic, recurring, inflammatory disease of the skin and soft tissue characterised by deep-seated nodules, sinus tracts and abscesses leading to fibrosis in the axillary, inguinal, breast-fold and anogenital regions. ${ }^{12}$ It is associated with

\section{Strengths and limitations of this study}

- This is a study on hidradenitis suppurativa (HS), a debilitating disease that causes substantial morbidity and quality-of-life impairment and for which there is low awareness.

- A large data set of US administrative claims data from both Commercial/Medicare and Medicaid were used to retrospectively examine prevalence, demographic/clinical characteristics, comorbidity burden, treatment patterns and disparities, healthcare resource utilisation and expenditures of patients with HS in the real-world.

- This study employed rigorous inclusion criteria, including a requirement for $\geq 3$ non-diagnostic outpatient or inpatient claims with a diagnosis code for HS, which conferred a higher positive predictive value for HS.

- Limitations include ascertainment, detection and misclassification bias; coding inaccuracies; and generalisability to patients with other/without insurance.

- Our study can be further used as a basis to understand the extent to which comorbidities contribute to the economic burden in patients with HS and health disparities that may exist across populations.

substantial pain and comorbidities, including metabolic, psychiatric and autoimmune disorders, as well as an increased risk of skin cancer. $^{13-5}$

Worldwide, reported prevalence rates of HS vary from $<1 \%^{36-10}$ to $4 \%^{11}$ of the population. However, the true prevalence has been difficult to ascertain because HS is likely to be underdiagnosed, and epidemiological estimates vary with study design, population and geographic location. ${ }^{12}$ Although the National Institutes of Health does not classify it as a rare disease, ${ }^{13}$ experts generally consider the prevalence to be $<1 \%$ of the US population. ${ }^{67}$

Current treatment for HS consists of topical and/or systemic antibiotics, hormonal interventions, analgesics and, in selected cases, immunosuppressants such as the tumour 
necrosis factor (TNF) inhibitor monoclonal antibody adalimumab, and surgical excision. ${ }^{14-16}$ However, symptom control and lesion resolution are inconsistent and often inadequate, which may lead to increased healthcare costs. Recent studies have shown that patients with HS utilised healthcare in high-cost settings (eg, emergency department (ED) and inpatient care) more frequently than patients with other chronic inflammatory skin conditions. ${ }^{1718}$

Previous analyses of claims data across various disease states have shown that substantial differences may exist between Medicaid (state level public assistance programme) and commercially insured populations in terms of epidemiology, patient characteristics, disease management and economic burden. ${ }^{19-22}$ As an example, compared with commercially insured patients, one analysis demonstrated that Medicaid patients with multiple sclerosis were younger, more likely to have comorbidities (eg, hypertension, diabetes) and less likely to receive disease-modifying therapies. ${ }^{20}$ In addition, the Medicaid population incurred substantially higher costs, associated with more frequent visits to the ED and a greater proportion of patients requiring one or more inpatient hospitalisations. Such discrepancies, which may be related in part to poorer access to expert care and therapies for Medicaid patients, are critical to identify because they could adversely impact clinical outcomes. The current administrative claims database analysis aims to increase our understanding of HS and specifically characterises the prevalence of this disease and the demographic/clinical characteristics, comorbidities, treatment patterns, healthcare resource utilisation and expenditures of Commercial and Medicare (federal programme designed to cover people older than 65 years in the USA) payors contrasted with Medicaid HS patients in the USA. The objective of our analysis was to provide a 'baseline' assessment of the HS treatment landscape before the US Food and Drug Administration (FDA) approval of biologics as a treatment option for HS.

\section{MATERIALS AND METHODS}

\section{Study design and population}

This was a retrospective, observational administrative claims data study. The earliest of three confirmed diagnoses of HS served as the index date, and claims were evaluated during the 12-month period before the index date (preindex period) and the 12-month period after the index date (postindex period).

Patients $\geq 12$ years of age on the index date with $\geq 3$ non-diagnostic outpatient or inpatient medical claims, ${ }^{23}$ which included a diagnosis code for HS (International Classification of Diseases, 9th Revision, Clinical Modification (ICD-9-CM) 705.83) in any position between 1 January 2008 and 31 December 2014, were included in the analysis. Non-diagnostic claims are those that are not potentially associated with a diagnostic workup used to rule out the presence of a condition, such as claims for laboratory tests. The rationale for requiring $\geq 3$ non-diagnostic claims with a diagnosis code for HS is that it yields a higher positive predictive value and greater assurance in the quality of the data set. ${ }^{23}$ At least 12 months of continuous enrolment with medical and pharmacy benefits during both the preindex and postindex periods were required for inclusion in the analysis.

\section{Data sources and measurements}

Administrative claims data from the IBM Watson Health MarketScan Commercial Claims and Encounters (Commercial), Medicare Supplemental (Medicare) and Multi-State Medicaid (Medicaid) databases were analysed. The Commercial and Medicare databases contain inpatient and outpatient medical and outpatient prescription drug information of employees and their dependents with employer-sponsored primary insurance and retirees with insurance paid by employers, respectively. Both the Medicare-paid and employer-paid portions of payment are included in the Medicare database. The Medicaid database contains records of inpatient and outpatient services, inpatient admissions and prescription drug claims for Medicaid beneficiaries from several geographically dispersed states.

\section{Study variables}

Patient demographic variables were obtained on the index date. A count of all unique 3-digit ICD-9-CM diagnosis codes and HS-related comorbidities were obtained for the preindex period. A binary flag variable was created for HS-related comorbid conditions (see online supplemental material for a full list of conditions). Patients were identified as having the condition if they had $\geq 1$ medical claim with an ICD-9-CM or ICD, 10th Revision, Clinical Modification (ICD-10-CM) diagnosis code for the condition.

Predefined pharmacological and surgical/interventional treatments and the proportion of patients who discontinued their initial non-biological treatment (defined as no refill of the medication within 45 days after the previous days' supply was exhausted) were evaluated. Concurrent medication use was also reported, defined as the proportion of patients on medication for $>1$ therapy class. Treatments were identified by the presence of a claim with a National Drug Code or Healthcare Common Procedure Coding System code and reported per patient in both the preindex and postindex periods (see online supplemental material for a full list of treatments). Claims with a procedure code for surgeries (laser, draining or incision and excision) during the preindex and postindex periods were captured and the number of patients with a claim for each treatment was reported separately.

HS-related healthcare costs were identified by the presence of an HS diagnosis (ICD-9-CM 705.83 or ICD-10-CM L73.2); a diagnosis of cellulitis, boils, fistula or abscesses; or an HS-related procedure on the claim. Costs (US\$2015) were measured in the preindex and postindex periods. Total healthcare, inpatient, outpatient 
(eg, ED, physician office, laboratory, pathology, imaging/ radiology, outpatient surgery and other outpatient claims), total outpatient pharmacy and biological TNF inhibitor and non-biological pharmacy costs were evaluated. For inpatient hospitalisations, HS must have been coded in the primary position or in a secondary position in conjunction with a primary diagnosis code for cellulitis, boils, fistula or abscesses.

\section{Patient and public involvement}

The data source for this study is a retrospective claims database, and all patients were deidentified. Thus, patients in the study population were not involved in the study design and were not informed of any study results. No new data were collected nor new patients recruited.

\section{Statistical analyses}

All variables were analysed separately for Commercial/ Medicare and Medicaid patients. Descriptive analyses were conducted on all study variables. Categorical variables were presented as the count and percentage of patients in each category. Continuous variables were summarised as mean, SD and median.

Prevalence was defined by the presence of patients with $\geq 1$ diagnosis of HS; patients could be counted in multiple years. Prevalence was reported for each individual year during the study period and was calculated as follows: (total cases of HS in reported year/total number of people in reported year), where the denominator represented any patient aged $\geq 12$ years with $\geq 1$ year of continuous enrolment with medical and pharmacy benefits during the study period. The prevalence includes both existing and newly diagnosed patients with HS in the reported year.

\section{RESULTS}

Patient demographics and clinical characteristics

A total of 11325 patients from the Commercial/Medicare database and 5164 patients from the Medicaid database met the selection criteria and were included in the analysis (figure 1). The mean (SD) age of patients was 37.4 (15.1) years and 28.3 (12.3) years in the Commercial/Medicare and Medicaid cohorts, respectively. As shown in table 1 , the majority of patients were female (Commercial/Medicare: 76.4\%; Medicaid: 85.9\%) and more than half in the Medicaid cohort were black $(54.8 \%)$.

The most common comorbidities in both cohorts during the preindex and postindex periods were cellulitis and psychiatric disorders (table 2). In the preindex period, cellulitis was observed in $34.1 \%$ of Commercial/ Medicare patients and $47.0 \%$ of Medicaid patients, and psychiatric disorders were noted in $24.3 \%$ and $52.2 \%$, respectively. Cardiovascular/metabolic disorders were also common in both Commercial/Medicare and Medicaid patients: hypertension (22.5\% and $23.9 \%)$, dyslipidemia ( $14.7 \%$ and $13.0 \%)$, diabetes mellitus type $2(12.3 \%$ and $13.9 \%)$ and obesity $(10.7 \%$ and $24.1 \%)$, respectively.

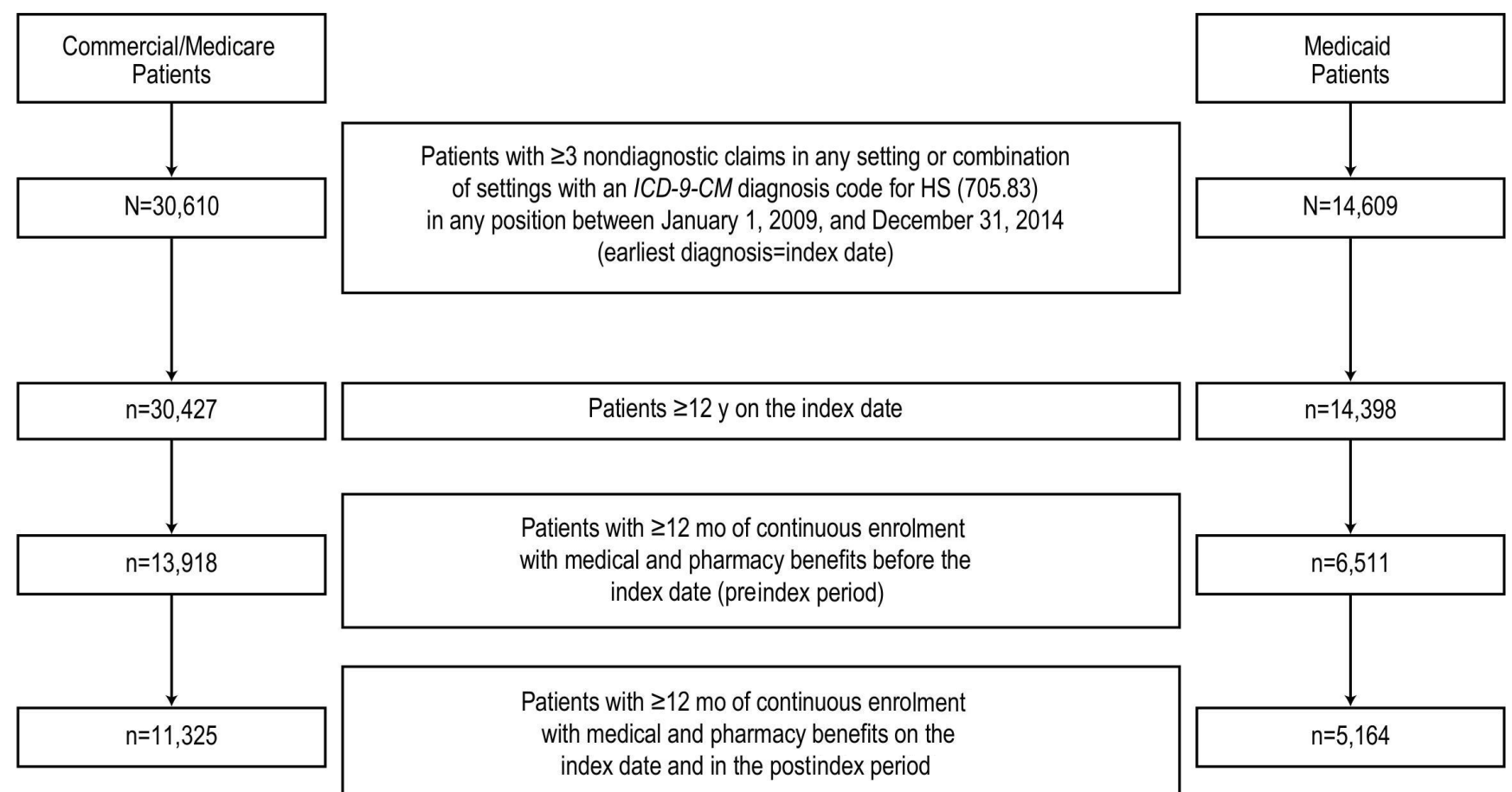

Figure 1 Hidradenitis suppurativa. Derivation of study population with HS. HS, hidradenitis suppurativa; ICD-9-CM, International Classification of Diseases, 9th Revision, Clinical Modification. 


\begin{tabular}{lll}
\hline Table 1 Patient demographics & & \\
\hline & $\begin{array}{l}\text { Commercial/ } \\
\text { Medicare } \\
(\mathbf{n}=\mathbf{1 1 3 2 5})\end{array}$ & $\begin{array}{l}\text { Medicaid } \\
(\mathbf{n}=5164)\end{array}$ \\
\hline Characteristic & $37.4(15.1)$ & $28.3(12.3)$ \\
\hline Age, years, mean (SD) & $8656(76.4)$ & $4438(85.9)$ \\
\hline Female, $\mathrm{n}(\%)$ & & \\
\hline Payer, $\mathrm{n}(\%)$ & $10881(96.1)$ & 0 \\
\hline Commercial & $444(3.9)$ & 0 \\
\hline Medicare & 0 & $5164(100)$ \\
\hline Medicaid & - & $2831(54.8)$ \\
\hline Race, $\mathrm{n}(\%)^{\star}$ & - & $1804(34.9)$ \\
\hline Black & - & $361(7.0)$ \\
\hline White & - & $123(2.4)$ \\
\hline $\begin{array}{l}\text { Other } \\
\text { Hispanic }\end{array}$ & - & $12(0.2)$ \\
\hline American Indian or Alaska Native & - & \\
\hline $\begin{array}{l}\text { Native Hawaiian or other Pacific } \\
\text { Islands }\end{array}$ & - & \\
\hline
\end{tabular}

*Race was reported in the Medicaid database only.

\section{Treatment patterns}

Overall, $86.8 \%$ of Commercial/Medicare and $90.1 \%$ of Medicaid patients received some form of treatment during both the preindex and postindex periods. Oral antibiotics and prescription pain medications were the most commonly prescribed medications preindex (Commercial/Medicare: $77.7 \%$ and $43.1 \%$; Medicaid: $80.9 \%$ and $59.7 \%$, respectively), and this increased by $\geq 10 \%$ postindex (table 3 ). Discontinuation of oral non-biologics was common $(68.6 \%-73.8 \%)$ (table 3$)$.

Biological TNF inhibitors were prescribed in $1.9 \%$ of patients in the Commercial/Medicare database and 0.8\% of patients in the Medicaid database during the preindex period, and increased to $2.7 \%$ and $1.0 \%$, respectively, after HS diagnosis (table 3 ).

Overall, $1.2 \%$ of Commercial/Medicare and $0.4 \%$ of Medicaid patients with HS did not receive any pharmacological treatment during the preindex and postindex periods. The most common surgical/interventional treatment was draining or incision surgery, rates of which increased from preindex (Commercial/Medicare: 16.1\%; Medicaid: 21.8\%) to postindex (Commercial/ Medicare: 23.9\%; Medicaid: $31.5 \%$ ). The proportions of patients treated with excision surgery were low preindex (Commercial/Medicare: 1.1\%; Medicaid: $0.9 \%$ ) but rose substantially during postindex (Commercial/Medicare: 19.9\%; Medicaid: 21.4\%). In both the preindex and postindex periods, $\leq 5 \%$ of patients were treated with laser surgery.

\section{Prevalence}

The estimated annual prevalence of HS in both databases was $<1 \%$ during the study period (2009-2014) but showed a gradual increase annually (figure 2). Over the 6-year study period, the annual detected prevalence increased from $0.066 \%$ to $0.098 \%$ in the Commercial/Medicare database and from $0.202 \%$ to $0.301 \%$ in the Medicaid database.

\section{HS-related healthcare utilisation and costs}

During the preindex period, $<1 \%$ of patients in both cohorts had an HS-related hospitalisation; however, that increased to $4.0 \%$ (Commercial/Medicare) and $4.8 \%$ (Medicaid) in the postindex period. Utilisation of outpatient services increased from $58.8 \%$ to $100 \%$ in the Commercial/Medicare cohort and from $65.6 \%$ to $99.9 \%$ in the Medicaid cohort. With the exception of ED services, the presence of services for outpatient HS-related surgeries, laboratory/pathology, imaging/radiology and outpatient pharmacy more than doubled between the preindex and postindex periods among both cohorts (table 4).

Total costs of care among HS patients increased from US $\$ 1349$ to US $\$ 4428$ (Commercial/Medicare) and US\$859 to US\$2662 (Medicaid) during the preindex to postindex periods, respectively. Among HS patients with $\geq 1$ service, the average number of inpatient admissions was unchanged between the preindex and postindex periods and inpatient costs decreased. However, the average number of outpatient claims approximately doubled among both cohorts between the preindex and postindex periods: 6.6 to 12.6 among Commercial/Medicare patients and 9.7 to 18.1 among Medicaid patients. In addition, mean (SD) outpatient costs more than doubled between the preindex and postindex periods in both cohorts (from US\$1036 (US\$3997) and US\$616 (US\$2280) to US\$2515 (US\$5799) and US\$1356 (US\$3029) in the Commercial/Medicare and Medicaid cohorts, respectively), with increases in ED, office, laboratory/pathology and HS-related surgery costs (table 4). Among patients using healthcare resources, inpatient costs still represented a higher proportion of the economic burden.

\section{DISCUSSION}

This study used US administrative claims data from both Commercial/Medicare and Medicaid patients with HS. Overall, patients were relatively young, with a female to male ratio of $\sim 3: 1$, consistent with other analyses. ${ }^{6} 71823$ This analysis confirmed the high comorbidity burden of patients with HS reported in previous studies, ${ }^{4} 1824$ with cellulitis and psychiatric disorders reported most commonly among all patients and at rates higher than those described in individuals without HS. ${ }^{25}{ }^{26}$ Components of metabolic syndrome were common such as obesity, diabetes, hyperlipidemia and hypertension; anaemia was also common. Further, analysis suggested that the comorbidity burden was more thoroughly documented in the postindex period than the preindex period.

The prevalence of clinically detected HS was low during the 6-year study period (2009-2014) but increased yearly. Prevalence estimates of HS are historically accepted as $\sim 1 \%$ and have been reported as high as $4 \% .{ }^{11}$ However, 
Table 2 Comorbidities in the preindex and postindex periods

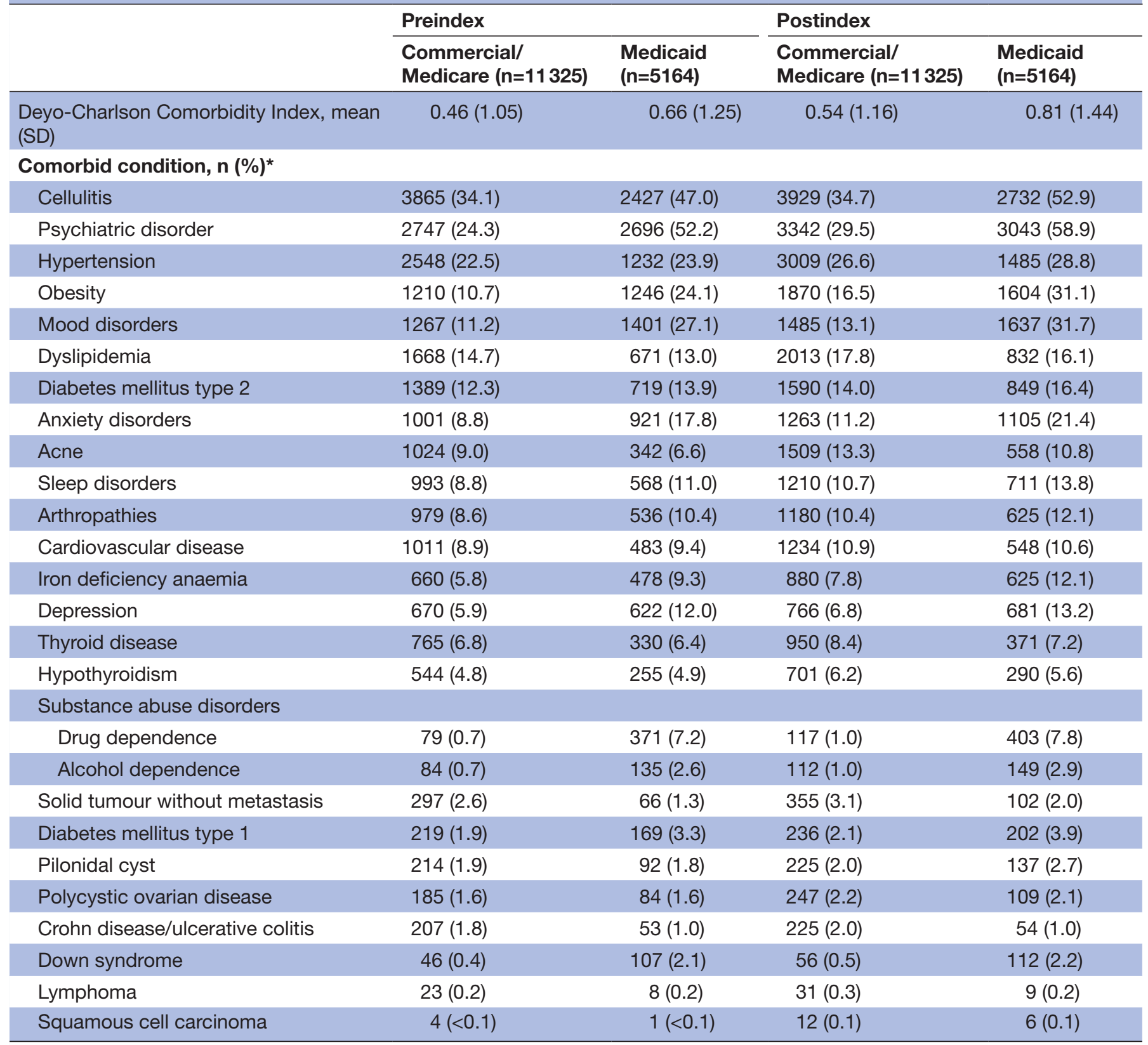

*Sorted by decreasing frequency in the postindex period (Commercial/Medicare and Medicaid populations combined).

the prevalence rate from our analysis $(<0.31 \%)$ and other recent reports suggest a rate substantially $<1 \%$. 369102728 Reasons for this discrepancy may be related to differences in study design (eg, prospective vs retrospective). The high prevalence rate of $4 \%$, for example, was based on prospective research in a selected sample in which patients were specifically examined for HS signs. ${ }^{11}$ Some previous studies focused on small geographic areas or limited populations (eg, hospitalised patients, those attending a specific clinic), 81112 whereas our study and several other recent claims analyses evaluated larger data sets. $^{3691027}$ HS may also be substantially undercoded in these large data sets, as it often goes undiagnosed for a decade or more after presentation and may alternatively be coded as abscesses or boils.

After antibiotics, non-steroidal anti-inflammatory drugs and prescription pain medications, specifically narcotics, were the two most prescribed classes of drugs in this study, and their use increased from the preindex to postindex periods. Although claims databases cannot capture treatment indications for prescriptions, the high rate of pain medication use is consistent with patient accounts describing $\mathrm{HS}$ as a painful disease. ${ }^{25}$ Overall, TNF inhibitors, including adalimumab, were not frequently prescribed ( $<2 \%$ overall) during the study period (20092014). Although this is a limitation of the analysis, it is not 
Table 3 Treatment patterns during the preindex and postindex periods

\begin{tabular}{|c|c|c|c|c|}
\hline \multirow[b]{2}{*}{ Treatment, n (\%) } & \multicolumn{2}{|l|}{ Preindex } & \multicolumn{2}{|l|}{ Postindex } \\
\hline & $\begin{array}{l}\text { Commercial/ } \\
\text { Medicare }(n=11325)\end{array}$ & $\begin{array}{l}\text { Medicaid } \\
(n=5164)\end{array}$ & $\begin{array}{l}\text { Commercial/ } \\
\text { Medicare }(n=11325)\end{array}$ & $\begin{array}{l}\text { Medicaid } \\
(\mathrm{n}=5164)\end{array}$ \\
\hline \multicolumn{5}{|l|}{ Pharmacological treatment } \\
\hline \multicolumn{5}{|l|}{ Biological TNF inhibitor } \\
\hline Adalimumab & $106(0.9)$ & $17(0.3)$ & $174(1.5)$ & $28(0.5)$ \\
\hline Other & $10(<0.1)$ & $3(<0.1)$ & $13(0.1)$ & $2(<0.1)$ \\
\hline \multicolumn{5}{|l|}{ Biological non-TNF inhibitor } \\
\hline Ustekinumab & $1(<0.1)$ & $1(<0.1)$ & $4(<0.1)$ & $1(<0.1)$ \\
\hline Anakinra & $1(<0.1)$ & $0(0)$ & $0(0)$ & $0(0)$ \\
\hline Narcotic & $4821(42.6)$ & $3039(58.8)$ & $6352(56.1)$ & $3737(72.4)$ \\
\hline Non-narcotic & $211(1.9)$ & $240(4.6)$ & 217 (1.9) & $271(5.2)$ \\
\hline \multicolumn{5}{|l|}{ Antibiotics } \\
\hline Oral & $8796(77.7)$ & $4176(80.9)$ & $10210(90.2)$ & $4890(94.7)$ \\
\hline Topical & $2224(19.6)$ & 1079 (20.9) & 4340 (38.3) & 2094 (40.5) \\
\hline Intravenous & $1369(12.1)$ & $1041(20.2)$ & $2199(19.4)$ & $1731(33.5)$ \\
\hline Patients on medications in $>1$ therapy class & $184(1.6)$ & $35(0.7)$ & $277(2.4)$ & $54(1.0)$ \\
\hline $\begin{array}{l}\text { Patients who discontinued oral non-biological } \\
\text { treatment }\end{array}$ & - & - & $8061(73.8)^{\star}$ & $3505(68.6)^{\star}$ \\
\hline
\end{tabular}

${ }^{*}$ Percentages are based on the number of patients whose initial medication was a non-biological treatment ( $\mathrm{n}=10927$ Commercial/Medicare; $\mathrm{n}=5108$ Medicaid).

NSAIDs, non-steroidal anti-inflammatory drugs; TNF, tumour necrosis factor.

surprising as the study period was chosen to provide an assessment of the disease burden and cost of HS before biologics became a treatment option for HS. TNF inhibitors did not obtain FDA approval for use in HS until December $2015 .^{29}$ Therefore, use of these agents during the preindex and postindex periods could have been used to treat comorbidities for which these therapies had been approved. It is also possible that some patients were prescribed TNF inhibitors off-label during the postindex period, although this was likely minimal because of physician reluctance in prescribing medications off-label and/ or reimbursement challenges.

During the study period, cessation of individual treatments was high, as evidenced by the $68.6 \%-73.8 \%$ of patients who discontinued treatment with oral non-biologics. Some of the treatment discontinuation may reflect the underlying fluctuation of $\mathrm{HS}$, which includes exacerbations and remissions and others may reflect prescriptions intended for discrete and limited time periods. However, this treatment pattern could also suggest a lack of efficacy or satisfaction with the prescribed therapies and demonstrate an unmet need in this population.

HS-related inpatient costs decreased between the preindex and postindex periods, whereas outpatient costs increased in both patient cohorts. Once patients were diagnosed with HS, they were likely managed on an outpatient basis, highlighting the importance of timely and accurate diagnosis to decrease the utilisation of highcost resources (ie, ED visits or inpatient admissions).

Comparisons between the Commercial/Medicare and Medicaid populations were descriptive in nature, with no inferential statistics performed to test a particular hypothesis. Although no definitive conclusions could therefore be made based on these comparisons, the two populations do serve as a good proxy for socioeconomic and income level, which are factors likely to influence 


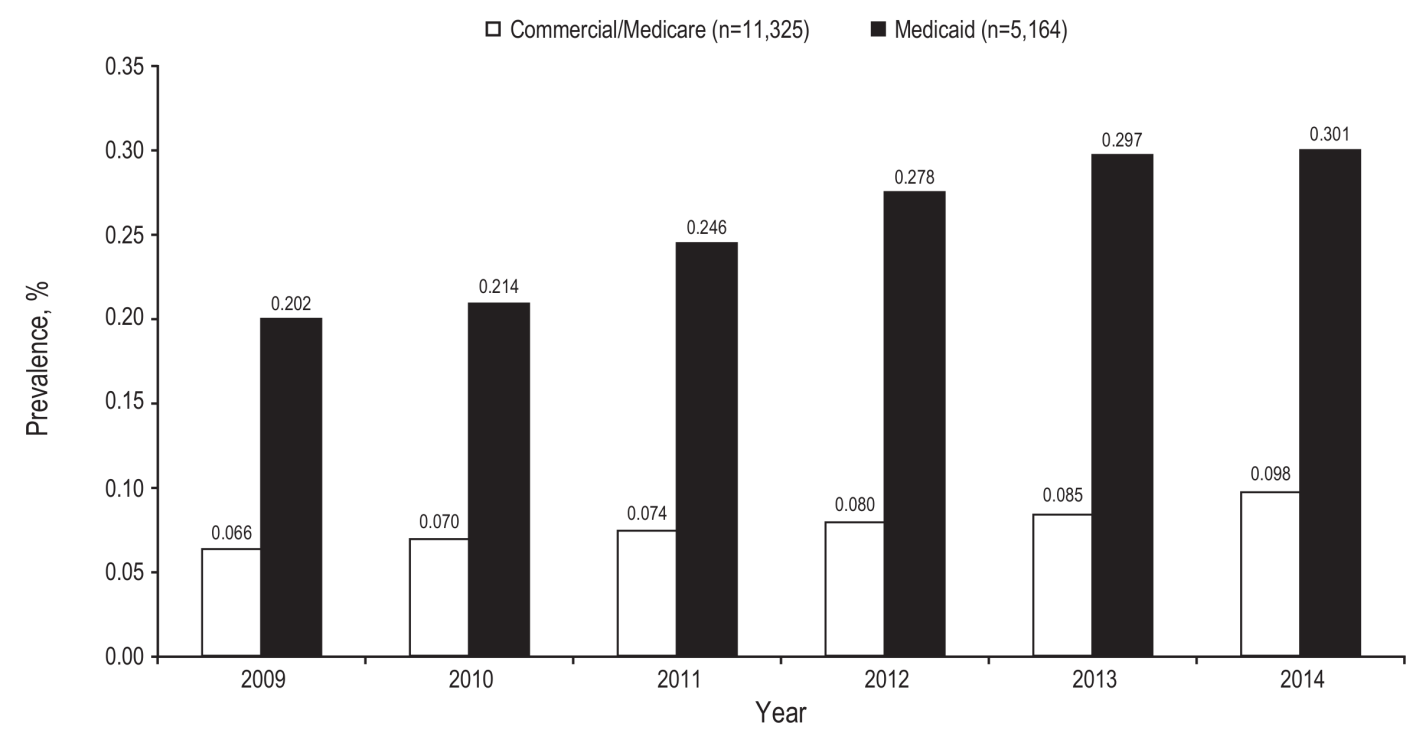

Figure 2 Hidradenitis suppurativa. Annual prevalence in the USA.

access to treatment, resource utilisation and expenditures. In the USA, Medicaid provides coverage for some individuals and families who have a lower income level, as well as for those with disabilities. It is worth noting that several differences appeared to exist between Commercial/Medicare and Medicaid patients in our analysis.
Medicaid patients had an annual detected prevalence 3-3.5 times higher than the prevalence of HS in the Commercial/Medicare population. This could possibly be attributed to the Medicaid cohort having a high proportion of black patients $(54.8 \%)$ as HS has been shown in retrospective analyses to be more common in

Table 4 HS-related utilisation and expenditures in the preindex and postindex periods

\begin{tabular}{|c|c|c|c|c|}
\hline \multirow{3}{*}{ 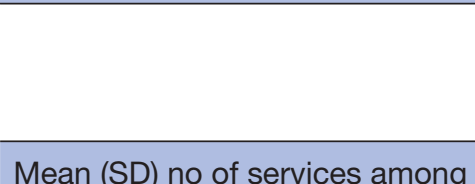 } & \multicolumn{2}{|l|}{ Preindex } & \multicolumn{2}{|l|}{ Postindex } \\
\hline & $\begin{array}{l}\text { Commercial/ } \\
\text { Medicare }(n=11325)\end{array}$ & $\begin{array}{l}\text { Medicaid } \\
(\mathrm{n}=5164)\end{array}$ & $\begin{array}{l}\text { Commercial/ } \\
\text { Medicare }(n=11325)\end{array}$ & $\begin{array}{l}\text { Medicaid } \\
(n=5164)\end{array}$ \\
\hline & \multicolumn{4}{|c|}{ Mean (SD) no of services among patients with $\geq 1$ service } \\
\hline Inpatient admissions & $1.3(0.7)$ & $1.1(0.4)$ & $1.3(0.6)$ & $1.4(0.9)$ \\
\hline Outpatient claims & $6.6(13.6)$ & $9.7(16.3)$ & $12.6(18.0)$ & $18.1(24.1)$ \\
\hline \multicolumn{5}{|c|}{ Mean (SD) expenditures among patients with $\geq 1$ service, US $\$ 2015$} \\
\hline Total inpatient & US\$31750 (41 641) & US\$26032 (50 055) & US\$23742 (33 780) & US\$17613 (34 139) \\
\hline $\mathrm{n}(\%)$ & $60(0.5)$ & $30(0.6)$ & $452(4.0)$ & $250(4.8)$ \\
\hline Total outpatient & US\$1036 (3997) & US\$616 (2280) & US\$2515 (5799) & US\$1356 (3029) \\
\hline $\mathrm{n}(\%)$ & $6662(58.8)$ & $3390(65.6)$ & $11320(100.0)$ & $5157(99.9)$ \\
\hline Emergency department & US\$1093 (1207) & US\$435 (703) & US\$1292 (1386) & US\$455 (754) \\
\hline n (\%) & $853(7.5)$ & $1325(25.7)$ & $1045(9.2)$ & 1749 (33.9) \\
\hline Outpatient office & US\$222 (261) & US\$143 (177) & US\$361 (349) & US\$217 (259) \\
\hline n (\%) & $4350(38.4)$ & $2004(38.8)$ & $11027(97.4)$ & 4815 (93.2) \\
\hline Laboratory and pathology & US\$153 (376) & US\$62 (97) & US\$276 (618) & US\$102 (294) \\
\hline n (\%) & $2325(20.5)$ & $1252(24.2)$ & $5333(47.1)$ & 2907 (56.3) \\
\hline Imaging or radiology & US\$607 (1349) & US\$142 (246) & US\$467 (1540) & US\$188 (351) \\
\hline n (\%) & $224(2.0)$ & $161(3.1)$ & $525(4.6)$ & $326(6.3)$ \\
\hline Outpatient HS-related surgery & US\$364 (780) & US\$236 (570) & US\$1205 (1951) & US\$511 (834) \\
\hline n (\%) & $1792(15.8)$ & $523(10.1)$ & 4348 (38.4) & $1820(35.2)$ \\
\hline
\end{tabular}

Mean (SD) expenditures are based on the $\mathrm{n}$ values shown, which represent the number of patients who used the service.

HS, hidradenitis suppurativa. 
blacks compared with whites ${ }^{30} 31$; race was not captured in our Commercial/Medicare cohort. The proportion of black patients reported in the Medicaid cohort is higher than previous reports from smaller patient populations. $^{3923}$ However, another recent database analysis reported that black patients accounted for $47.3 \%$ of the total HS population studied, ${ }^{7}$ consistent with our findings. Our analysis also showed that Medicaid patients were younger than Commercial/Medicare patients yet had more comorbidities (eg, obesity, psychiatric) and higher rates of prescription pain medication use, ED visits and hospitalisation. As mentioned earlier, the lack of continuous treatment for Medicaid patients may reflect the natural evolution of HS; however, in other cases (eg, inadequate efficacy and/or treatment satisfaction), it could indicate a need for improved management strategies for this at-risk group, which would benefit the patient and reduce burden on the healthcare system. Similar differences between Commercial/Medicare and Medicaid populations have been observed in previous claims analyses of other disease states, ${ }^{19-22}$ increasing the generalisability of our findings.

Potential limitations of this study include those inherent to database analyses, which rely on administrative claims subject to coding restrictions and entry errors. Further, undercoding is specifically recognised for HS and obesity, ${ }^{23} 32$ both relevant to this analysis and patient population. The analysis was only descriptive in nature, without control groups, and stratification by disease severity was not possible. It would have been interesting to compare findings before versus after the approval of biologics for HS, but 5-year postapproval data are not yet mature enough for analysis. Strengths of our study were that it employed more rigorous inclusion criteria, including a requirement for $\geq 3$ non-diagnostic outpatient or inpatient claims with a diagnosis code for HS, which conferred a higher positive predictive value for $\mathrm{HS}^{23}$ Another limitation is that although prescriptions and fill data were captured, claims analyses cannot confirm the proper use of or adherence to medications, both of which could influence subsequent treatment patterns. Further, our findings may not be generalisable to patients with HS with other types of insurance or those without health insurance. Lastly, HS is underdiagnosed and misdiagnosed and, therefore, prevalence may be underreported. Estimates of prevalence were subject to detection bias in this study, because they were reliant on retrospective analysis of secondary data.

This study identified key areas for additional research. For example, the extent to which comorbidities contribute to the economic burden in patients with HS is unknown. In addition, the impact on baseline descriptive analyses in the time period after biological approval (ie, after FDA approval of adalimumab) and with the advent of other FDA-approved medications for HS should be explored.

\section{CONCLUSIONS}

This large claims database analysis found a low prevalence of HS in the USA, with high comorbidity burden and outpatient healthcare resource utilisation. Among patients using healthcare resources, outpatient costs increased but inpatient costs still represented a higher proportion of the economic burden. Large proportions of patients with HS discontinue treatments, suggesting a lack of efficacy or satisfaction with medications available during the period evaluated.

Acknowledgements This study was funded by Novartis Pharmaceuticals Corporation. Medical writing assistance was provided by Jessica Holzhauer, DVM, and Michael S. McNamara, MS, of C4 MedSolutions, LLC (Yardley, PA), a CHC Group company, with funding from Novartis Pharmaceuticals Corporation. JH was an employee of C4 MedSolutions at the time of manuscript preparation.

Contributors JM and AV initiated and designed the study. AS-N, TW and AV carried out data analysis. JM, AV, AS-N, TW and AK contributed to writing of the manuscript, commenting on the draft and approving the final version of the manuscript. The data source for this study is a retrospective claims database and thus there are no patient or public contributors.

Funding This work was supported by Novartis Pharmaceuticals Corporation.

Competing interests AK has received honoraria as a consultant for AbbVie and Novartis; and received grants and/or funding for research or a fellowship programme from AbbVie and Janssen. JM is an employee of Novartis Pharmaceuticals Corporation. AS-N is an employee of IBM Watson Health. AV and TW were employees of IBM Watson Health at the time the study was conducted.

Patient consent for publication Not required.

Provenance and peer review Not commissioned; externally peer reviewed.

Data availability statement The data used for this study are proprietary and only available through a licensing data use agreement process. This process ensures that confidentiality of the data contributors is maintained and that the data are used appropriately. All patients in the database are de-identified, and the identities of data contributors are removed.

MarketScan Research Database can be licensed by researchers via https://www. ibm.com/us-en/marketplace/marketscan-research-databases. Alternatively, IBM Watson Health can be contacted regarding a license to use the MarketScan data.

Open access This is an open access article distributed in accordance with the Creative Commons Attribution Non Commercial (CC BY-NC 4.0) license, which permits others to distribute, remix, adapt, build upon this work non-commercially, and license their derivative works on different terms, provided the original work is properly cited, appropriate credit is given, any changes made indicated, and the use is non-commercial. See: http://creativecommons.org/licenses/by-nc/4.0/.

ORCID iD

Jessica Marvel http://orcid.org/0000-0002-0757-5865

\section{REFERENCES}

1. Revuz JE, Jemec GBE. Diagnosing hidradenitis suppurativa. Dermatol Clin 2016;34:1-5.

2. Jemec GBE. Clinical practice. hidradenitis suppurativa. N Engl J Med 2012;366:158-64.

3. Shlyankevich J, Chen AJ, Kim GE, et al. Hidradenitis suppurativa is a systemic disease with substantial comorbidity burden: a chart-verified case-control analysis. J Am Acad Dermatol 2014;71:1144-50.

4. Kohorst JJ, Kimball AB, Davis MDP. Systemic associations of hidradenitis suppurativa. J Am Acad Dermatol 2015;73(5 Suppl 1):S27-S35.

5. Wolkenstein P, Loundou A, Barrau K, et al. Quality of life impairment in hidradenitis suppurativa: a study of 61 cases. J Am Acad Dermatol 2007;56:621-3.

6. Cosmatos I, Matcho A, Weinstein R, et al. Analysis of patient claims data to determine the prevalence of hidradenitis suppurativa in the United States. J Am Acad Dermatol 2013;68:412-9. 
7. Davis SA, Lin H-C, Balkrishnan R, et al. Hidradenitis suppurativa management in the United States: an analysis of the National ambulatory medical care survey and MarketScan Medicaid databases. Skin Appendage Disord 2015;1:65-73.

8. Revuz JE, Canoui-Poitrine F, Wolkenstein P, et al. Prevalence and factors associated with hidradenitis suppurativa: results from two case-control studies. J Am Acad Dermatol 2008;59:596-601.

9. McMillan K. Hidradenitis suppurativa: number of diagnosed patients, demographic characteristics, and treatment patterns in the United States. Am J Epidemiol 2014;179:1477-83.

10. Garg A, Kirby JS, Lavian J, et al. Sex- and age-adjusted population analysis of prevalence estimates for hidradenitis suppurativa in the United States. JAMA Dermatol 2017;153:760-4.

11. Jemec GB, Heidenheim M, Nielsen NH. The prevalence of hidradenitis suppurativa and its potential precursor lesions. J Am Acad Dermatol 1996;35:191-4.

12. Miller IM, McAndrew RJ, Hamzavi I. Prevalence, risk factors, and comorbidities of hidradenitis suppurativa. Dermatol Clin 2016;34:7-16.

13. Genetic and Rare Diseases Information Center. National Institutes of health. hidradenitis suppurativa. Available: https://rarediseases.info. nih.gov/diseases/6658/hidradenitis-suppurativa [Accessed 20 Mar 2017].

14. Gulliver W, Zouboulis CC, Prens E, et al. Evidence-Based approach to the treatment of hidradenitis suppurativa/acne inversa, based on the European guidelines for hidradenitis suppurativa. Rev Endocr Metab Disord 2016;17:343-51.

15. Zouboulis CC, Desai N, Emtestam L, et al. European S1 guideline for the treatment of hidradenitis suppurativa/acne inversa. J Eur Acad Dermatol Venereol 2015;29:619-44.

16. Kimball AB, Okun MM, Williams DA, et al. Two phase 3 trials of adalimumab for hidradenitis suppurativa. $N$ Engl J Med 2016;375:422-34.

17. Khalsa A, Liu G, Kirby JS. Increased utilization of emergency department and inpatient care by patients with hidradenitis suppurativa. J Am Acad Dermatol 2015;73:609-14.

18. Kirby JS, Miller JJ, Adams DR, et al. Health care utilization patterns and costs for patients with hidradenitis suppurativa. JAMA Dermatol 2014;150:937-44.

19. Smoyer-Tomic KE, Amato AA, Fernandes AW. Incidence and prevalence of idiopathic inflammatory myopathies among commercially insured, Medicare supplemental insured, and Medicaid enrolled populations: an administrative claims analysis. BMC Musculoskelet Disord 2012;13:103.
20. Livingston $\mathrm{T}$, Fay $\mathrm{M}$, lyer $\mathrm{R}$, et al. Quantifying differences in health care consumption for the management of multiple sclerosis within privately and publicly insured health care programs. J Manag Care Spec Pharm 2016;22:1385-91.

21. Krishnarajah G, Carroll C, Priest J, et al. Burden of vaccinepreventable disease in adult Medicaid and commercially insured populations: analysis of claims-based databases, 2006-2010. Hum Vaccin Immunother 2014;10:2460-7.

22. Lang K, Patel AA, Munsell M, et al. Recurrent hospitalization and healthcare resource use among patients with deep vein thrombosis and pulmonary embolism: findings from a multi-payer analysis. J Thromb Thrombolysis 2015;39:434-42.

23. Kim GE, Shlyankevich J, Kimball AB. The validity of the diagnostic code for hidradenitis suppurativa in an electronic database. $\mathrm{Br} \mathrm{J}$ Dermatol 2014;171:338-42.

24. Jemec GBE, Guérin A, Kaminsky M, et al. What happens after a single surgical intervention for hidradenitis suppurativa? A retrospective claims-based analysis. J Med Econ 2016;19:710-7.

25. Ellis Simonsen SM, van Orman ER, Hatch BE, et al. Cellulitis incidence in a defined population. Epidemiol Infect 2006;134:293-9.

26. Shavit E, Dreiher J, Freud T, et al. Psychiatric comorbidities in 3207 patients with hidradenitis suppurativa. J Eur Acad Dermatol Venereol 2015;29:371-6.

27. Sung S, Kimball AB. Counterpoint: analysis of patient claims data to determine the prevalence of hidradenitis suppurativa in the United States. J Am Acad Dermatol 2013;69:818-9.

28. Zimman S, Comparatore MV, Vulcano AF, et al. Hidradenitis suppurativa: estimated prevalence, clinical features, concomitant conditions, and diagnostic delay in a university teaching hospital in Buenos Aires, Argentina. Actas Dermosifiliogr 2019;110:297-302.

29. United States food and drug administration. supplement approval: bla 125057/S-393, 2015. Available: http://www.accessdata.fda.gov/ drugsatfda_docs/appletter/2015/125057Orig1s393ltr.pdf [Accessed 20 Mar 2017].

30. Reeder VJ, Mahan MG, Hamzavi IH. Ethnicity and hidradenitis suppurativa. J Invest Dermatol 2014;134:2842-3.

31. Vlassova N, Kuhn D, Okoye GA. Hidradenitis suppurativa disproportionately affects African Americans: a single-center retrospective analysis. Acta Derm Venereol 2015;95:990-1.

32. Quan H, Li B, Saunders LD, et al. Assessing validity of ICD-9-CM and ICD-10 administrative data in recording clinical conditions in a unique dually coded database. Health Serv Res 2008;43:1424-41. 